ORIGINAL ARTICLE

\title{
Tumour size and vascular invasion predict distant metastasis in stage I breast cancer. Grade distinguishes early and late metastasis
}

\author{
P J Westenend, C J C Meurs, R A M Damhuis
}

J Clin Pathol 2005;58:196-201. doi: 10.1136/icp.2004.018515

See end of article for authors' affiliations

.....................

Correspondence to: Dr P J Westenend, Pathologisch Laboratorium voor Dordrecht eo, Laan van Londen 1800, 3315 HG Dordrecht, The Netherlands; pwestenend@paldordt. com

Accepted for publication 13 August 2004 mend adjuvant systemic treatment (AST) for women with high Background: Recent Dutch guidelines recommend adjuvant systemic treatment (AST) for women with high
grade stage I breast carcinoma $\geqslant 1 \mathrm{~cm}$. High grade is defined as Bloom and Richardson grade 3 (B\&R3), Nottingham modification, or mitotic activity (MAI) $\geqslant 10 / 1.59 \mathrm{~mm}^{2}$.

Aims: To investigate the validity of these histological prognostic factors as the exclusive defining criteria. Materials/methods: Fifty patients with stage I breast carcinoma who developed distant metastases and 50 matched controls without metastasis were studied; none had received AST.

Results: Cases more often had tumours $\geqslant 1 \mathrm{~cm}(p=0,019)$, B\&R3 tumours $(p=0.059)$, grade 3 nuclei $(p=0.005)$, and vascular invasion $(p=0.007)$. No differences were found for MAI $\geqslant 10(p=0.46)$. In multivariate analysis, the only significant variables were vascular invasion and tumour size (odds ratios: 8.21 and 5.35, respectively). In a separate analysis, the 50 cases were divided into 25 patients with early and 25 with late metastasis. Those with early metastasis more often had B\&R3 tumours $(p=0.009)$ and grade 3 nuclei $(p=0.006)$. No differences were found for tumours $\geqslant 1 \mathrm{~cm}$, vessel invasion, or $M A l \geqslant 10$. Using the present Dutch guidelines for AST, based on B\&R3, 20 cases and 11 controls would have received AST. Based on MAI $\geqslant 10,14$ cases and 11 controls would have received AST.

Conclusions: Tumour size and vessel invasion are the best prognostic factors for disease free survival in patients with stage I breast cancer. Dutch selection criteria for AST for these patients need to be improved. Some prognostic factors are time dependent, making their use as selection criteria for AST more complicated.
A djuvant systemic treatment (AST) and/or hormonal treatment can improve survival in women with breast cancer, and this treatment is generally offered to all node positive patients. However, in node negative patients, the benefits of AST are smaller and must be balanced against the associated toxicity. This is especially the case in women with stage I (TINOMO) breast cancer. Survival in these patients is good, with excellent 10 year overall survival. ${ }^{1-4}$ Several histological factors have been described that identify patients with stage I breast cancer with a relatively worse prognosis who might benefit from AST as opposed to those with an excellent prognosis who could be spared the side effects of this treatment. ${ }^{5}$ Among these factors are tumour size, tumour grade, mitotic index, and vascular invasion.

\section{"Some histological prognostic factors, such as vessel invasion, that might be of importance, especially in node negative patients, have not been incorporated into the Dutch guidelines"}

In the Netherlands, recent guidelines recommend AST and/ or hormonal treatment for all node positive patients and those node negative patients with a tumour size larger than $3 \mathrm{~cm}{ }^{6}$ AST is not recommended for node negative patients with a tumour smaller than $1 \mathrm{~cm}$. For those node negative patients with a tumour size from 1 to $3 \mathrm{~cm}$, adjuvant treatment is recommended for those with high grade tumours. Tumour grade is defined by the Nottingham modification of the Bloom and Richardson score or the mitotic activity index (MAI). The Nottingham modification of the Bloom and Richardson score is widely used and has already been reported. ${ }^{7}$ It is a scoring system that looks at the growth pattern (tubule formation) of a tumour, the pleomorphism of the nuclei, and the mitotic activity. The scores are added and translated into three grades. In the Netherlands, the use of MAI $\geqslant 10 / 1.59 \mathrm{~mm}^{2}$, which is the same as a score of 3 points for mitotic activity in the Nottingham modification of the Bloom and Richardson score, has been advocated as a good alternative. ${ }^{8}$ However, the MAI has not been widely studied and the counting of mitotic figures is not as simple as it seems. ${ }^{9}$ Results are influenced by many factors, including time between removal of the tissue and fixation, speed of fixation, selection of fields for counting mitotic figures, the definition of a mitotic figure, and tumour heterogeneity. Another important issue is the setting of a threshold value.

Some histological prognostic factors, such as vessel invasion, that might be of importance, especially in node negative patients, have not been incorporated into the Dutch guidelines. Lymph vessel invasion has been incorporated as a prognostic factor into the Canadian guidelines for adjuvant treatment in node negative breast cancer. ${ }^{10}$ However others, although acknowledging the prognostic value of histological factors such as tumour type and grade, seem to use only tumour size in small node negative breast cancer. ${ }^{11}$ In addition, because breast cancer may have recurrences over a long period of time, prognostic factors that are significant in studies with a short term follow up might not be significant with longterm follow up. The aim of our present study was to assess the validity of the histological prognostic factors incorporated into the Dutch guidelines for adjuvant treatment and to test whether some of the factors have a

Abbreviations: AST, adjuvant systemic treatment; DCIS, ductal carcinoma in situ; DFS, disease free survival; MAI, mitotic activity index 
Table 1 Univariate analysis of prognostic factors comparing women with stage I breast cancer who do (cases) or do not (controls) have distant metastases

\begin{tabular}{|c|c|c|c|}
\hline Variable & Controls (n) & Cases (n) & p Value \\
\hline \multicolumn{4}{|l|}{ Age } \\
\hline$<50$ & 13 & 16 & \\
\hline $50-69$ & 30 & 24 & \\
\hline $70+$ & 7 & 10 & 1.000 \\
\hline \multicolumn{4}{|l|}{ Side } \\
\hline Left & 26 & 23 & \\
\hline Right & 24 & 27 & 0.689 \\
\hline \multicolumn{4}{|l|}{ Tumour grade } \\
\hline Well/moderate & 13 & 9 & \\
\hline Poor/undifferentiated & 22 & 28 & \\
\hline Unknown & 15 & 13 & 0.452 \\
\hline \multicolumn{4}{|l|}{ Tumour size } \\
\hline 1: $2 \mathrm{~cm}$ & 1 & 2 & \\
\hline $1 \mathrm{~A}: \leqslant 0.5 \mathrm{~cm}$ & 1 & 2 & \\
\hline $1 \mathrm{~B}:>0.5$ to $\leqslant 1 \mathrm{~cm}$ & 17 & 11 & \\
\hline $1 \mathrm{C}:>1$ to $<2 \mathrm{~cm}$ & 31 & 35 & 0.576 \\
\hline \multicolumn{4}{|l|}{ Type of surgery } \\
\hline Mastectomy & 19 & 25 & \\
\hline Lumpectomy & 31 & 25 & 0.314 \\
\hline \multicolumn{4}{|l|}{ Radiotherapy } \\
\hline Yes & 33 & 26 & \\
\hline No & 17 & 24 & 0.222 \\
\hline \multicolumn{4}{|l|}{ Screen detected } \\
\hline No & 33 & 39 & \\
\hline Yes & 17 & 11 & 0.265 \\
\hline \multicolumn{4}{|l|}{ Incidence period } \\
\hline 1988-1991 & 14 & 12 & \\
\hline 1992-1997 & 36 & 38 & 0.820 \\
\hline
\end{tabular}

prognostic value that is dependent on the duration of follow up.

\section{MATERIALS AND METHODS}

Follow up data for patients with stage I breast cancer who were investigated at one of the local pathology laboratories (Pathologisch Laboratorium voor Dordrecht eo) were collected from the Rotterdam Cancer Registry, the Netherlands. This laboratory serves several hospitals in the area. Patients with a synchronous or metachronous breast carcinoma were excluded. Completeness of follow up was defined as a known date of death, last follow up visit after 1 January 1999, or a follow up period of at least 10 years. Patients were either treated by mastectomy or by lumpectomy, followed by radiotherapy. All patients underwent a complete axillary lymph node dissection and none of the patients received AST. Between 1988 and 1997, 561 patients were available in total. Complete follow up data were available for $96.3 \%$ of the patients. In this period, 77 patients died and 66 patients developed distant metastases.

Because of the low number of patients with distant metastases, a case-control study was designed for a detailed evaluation of histological prognostic factors. Cases were defined as patients with distant metastases. Controls were matched to cases for the time of diagnosis and the hospital where the patient underwent surgery. The follow up time for controls was always longer than for cases. In the case-control study, three pairs were excluded because the tumour size of the cases as measured from the slides was larger than $2 \mathrm{~cm}$. One pair was excluded because in the case a micrometastasis was found on evaluation of the lymph nodes. In one pair the control was replaced because the tumour as measured from the slides was larger than $2 \mathrm{~cm}$, and in another pair the control was replaced because a micrometastasis was found on evaluation of the lymph nodes. The final analysis was based on 50 pairs with a maximum tumour diameter of $2 \mathrm{~cm}$ as measured from the slides and no (micro)metastases on evaluation of the lymph nodes. Follow up data and the type of operation-mastectomy or lumpectomy-were taken from the Rotterdam Cancer Registry. In the study period, tumours were not always graded and there was no agreement upon which grading system should be used. Tumour size was determined macroscopically in the pathology specimen and was sometimes estimated instead of being measured. Therefore, all original slides were reviewed by one pathologist without knowledge of the outcome.

All tissues were formalin fixed and paraffin wax embedded. Slides from tissue that had been frozen were not used in our analysis. The size of the tumours was taken from the microscope slides and tumours larger than $2 \mathrm{~cm}$ were excluded from our study. The tumour type was recorded as ductal not otherwise specified or as a special histological type-for example, infiltrating lobular carcinoma. A histological grade was attributed to all tumours, including special

Table 2 Univariate analysis of prognostic factors after pathological revision

\begin{tabular}{|c|c|c|c|}
\hline Variable & $\begin{array}{l}\text { Controls } \\
\text { (n) }\end{array}$ & Cases (n) & $\mathrm{p}$ Value \\
\hline \multicolumn{4}{|l|}{ Tumour size } \\
\hline Continuous variable & & & 0.0012 \\
\hline \multicolumn{4}{|l|}{ Tumour size } \\
\hline$\leqslant 1 \mathrm{~cm}$ & 15 & 7 & \\
\hline$>1$ and $\leqslant 1.5$ & 25 & 24 & \\
\hline$>1.5$ and $\leqslant 2 \mathrm{~cm}$ & 10 & 19 & 0.017 \\
\hline \multicolumn{4}{|l|}{ Tumour size } \\
\hline$<1 \mathrm{~cm}$ & 10 & 3 & \\
\hline$\geqslant 1 \mathrm{~cm}$ & 40 & 47 & 0.074 \\
\hline \multicolumn{4}{|l|}{ BR grade } \\
\hline 1 & 19 & 11 & \\
\hline 2 & 19 & 19 & \\
\hline 3 & 12 & 20 & 0.043 \\
\hline \multicolumn{4}{|l|}{ BR grade } \\
\hline 1 or 2 & 38 & 30 & \\
\hline 3 & 12 & 20 & 0.133 \\
\hline \multicolumn{4}{|l|}{ MAl } \\
\hline Continuous variable & & & 0.0393 \\
\hline \multicolumn{4}{|l|}{ MAl } \\
\hline$<10$ & 39 & 36 & \\
\hline$\geqslant 10$ & 11 & 14 & 0.644 \\
\hline \multicolumn{4}{|l|}{ Mitotic score (BR) } \\
\hline 1 & 32 & 26 & \\
\hline 2 & 7 & 10 & \\
\hline 3 & 11 & 14 & 0.292 \\
\hline \multicolumn{4}{|l|}{$\begin{array}{l}\text { Nuclear pleomorphism } \\
\text { score (BR) }\end{array}$} \\
\hline 1 & 8 & 5 & \\
\hline 2 & 27 & 17 & \\
\hline 3 & 15 & 28 & 0.020 \\
\hline \multicolumn{4}{|c|}{ Tubule formation score (BR) } \\
\hline 1 & 9 & 3 & \\
\hline 2 & 10 & 9 & \\
\hline 3 & 31 & 38 & 0.063 \\
\hline \multicolumn{4}{|l|}{ Tumour type } \\
\hline IDC & 41 & 43 & \\
\hline ILC & 5 & 5 & \\
\hline Other & 4 & 2 & 0.780 \\
\hline \multicolumn{4}{|l|}{ Multifocal } \\
\hline No & 46 & 45 & \\
\hline Yes & 4 & 5 & 1.000 \\
\hline \multicolumn{4}{|l|}{ Vessel invasion } \\
\hline No & 49 & 40 & \\
\hline Yes & 1 & 10 & 0.008 \\
\hline \multicolumn{4}{|l|}{ Extensive DCIS } \\
\hline No & 40 & 36 & \\
\hline Yes & 10 & 14 & 0.482 \\
\hline \multicolumn{4}{|l|}{ DCIS grade } \\
\hline 0 & 40 & 36 & 0.074 ( 3 versus 0 \\
\hline 1 or 2 & 8 & 5 & 1, 2: 0.051 Fisher) \\
\hline 3 & 2 & 9 & \\
\hline
\end{tabular}

BR, Bloom and Richardson; DCIS, ductal carcinoma in situ; IDC, invasive ductal carcinoma; ILC, invasive lobular carcinoma; MAI, mitotic activity index. 
histological types. If the pathology report noted that there was more than one tumour, this was recorded and the largest tumour was graded. The data from the pathology report were insufficient to make a distinction between multifocal and multicentric tumours. For all tumours the scores for tubule formation, nuclear pleomorphism, and the MAI were recorded and the final grade defined by the Nottingham modification of the Bloom and Richardson system. ${ }^{72}$ In addition, the number of mitotic figures was recorded. Mitotic figures were counted in eight randomly selected high power fields (final magnification, $\times 400$; field diameter, $0.5 \mathrm{~mm}$ ) at the periphery of the tumour, and care was taken to avoid counting apoptotic figures. Vascular invasion was recorded as present or not present. Vascular invasion had to be outside the main tumour in spaces with endothelial lining and was mostly near small muscular blood vessels. The presence of ductal carcinoma in situ (DCIS) was recorded if 10 or more ducts were affected. In addition, DCIS was graded as described previously, ${ }^{13}$ the presence or absence of comedo necrosis was recorded, and the presence or absence of calcifications in DCIS was also recorded. The number of lymph nodes was taken from the pathology report; all nodes were re-examined for the presence of metastasis and if present the patient was excluded from our study.

Univariate analysis was performed using $\chi^{2}$ statistics. The Mantel-Haenszel $\chi^{2}$ test was used for ordinal variables, the Kruskal-Wallis test for continuous variables, and the Fisher exact test for comparisons involving small cell numbers. Multivariate analysis was performed using conditional logistic regression. Only variables significantly improving the fit of the model $(p<0.05)$ were included in the final model. Odds ratios were calculated together with 95\% confidence interval and represent the relative risk compared with the reference category.

\section{RESULTS}

We compared the data registered in the Rotterdam Cancer Registry of patients with distant metastases (cases) with controls-those patients without distant metastases (table 1). There were no significant differences between cases and controls for age at the time of diagnosis, side of involvement, tumour grade, tumour size, type of surgery, radiotherapy, method of detection, and incidence period. In this database, tumour grade and size are taken from the original pathology report. The median follow up time of the cases until distant metastasis was 3.7 years, the median follow up time of the controls was 6.6 years.

Table 2 shows the results of the univariate analysis of the pathological revision. Data were analysed in several ways for reasons of comparison with published data or the Dutch guideline for adjuvant treatment. Cases had significantly larger tumours than controls (table 2), whether size was analysed as a continuous variable or whether the data were subdivided into three or two groups. The Bloom and Richardson tumour grade was significantly different when analysed in three groups, as is customary, with cases having a higher grade. However, when grade 1 and 2 were collapsed

\begin{tabular}{|c|c|c|}
\hline Variable & OR & $95 \% \mathrm{Cl}$ \\
\hline \multicolumn{3}{|l|}{ Vessel invasion } \\
\hline No & 1 & \\
\hline Yes & 8.21 & (1.015 to 66.417$)$ \\
\hline \multicolumn{3}{|l|}{ Tumour size } \\
\hline For each $1 \mathrm{~cm}$ increase & 5.35 & (1.390 to 20.625$)$ \\
\hline
\end{tabular}

into one grade, as is done in the Dutch guidelines, this resulted in no significant differences between cases and controls. The MAI was significantly different between groups when analysed as a continuous variable. However, when analysed in two groups $(<10$ and $\geqslant 10$, as in the Dutch guidelines) or three groups (as in the mitotic score of the Nottingham modification of the Bloom and Richardson grading system), no significant differences were found. Significant differences were found for the nuclear pleomorphism score, with cases more often being high grade, but not for the tubule formation score. No significant differences were seen for histological tumour type or multifocal tumours. Vessel invasion was significantly different between cases and controls. There were no differences in extensive DCIS or DCIS grade between groups.

Table 3 shows the results of the multivariate analysis of data from the pathological revision, and only significant data are shown. As can be seen, only tumour size and vessel invasion were retained from the results in table 2 .

The numbers of lymph nodes recovered from the axillary dissection were not different between cases and controls. For both groups the median number was 11 (range, 1-24), and the mean number was 10.9 for the cases and 11.3 for controls. In four cases and four controls the number of lymph nodes was five or less and in 18 cases and 17 controls the number was 13 or more.

The data from the pathological review were used to see which patients would have been selected for adjuvant treatment according to the Dutch guidelines (table 4). In these guidelines, adjuvant treatment is recommended for patients whose $\mathrm{Tl}$ tumours are $1 \mathrm{~cm}$ or larger, with a Bloom and Richardson grade 3 and/or MAI $\geqslant 10$. The selection of patients for adjuvant treatment based on Bloom and Richardson tumour grade was superior to selection based on MAI. Combining grade and MAI did not improve the selection of cases and selected more controls.

Because several authors have reported that prognostic factors can be time dependent, a separate analysis was performed for prognostic factors in cases. Cases were divided into two groups-those with early distant metastasis and those with late distant metastasis-and differences in prognostic factors were tested. Early metastasis was defined as distant metastasis occurring before the median time of 3.7 years, and late metastasis as metastasis occurring after 3.7 years. Table 5 shows the results of this analysis. There were striking differences between early and late distant metastasis for the Bloom and Richardson grade, whether analysed in three grades, as is conventional, or after collapsing grade 1 and 2 into one grade, as is done in the Dutch guidelines. High grade tumours were associated with early distant metastasis. Significant differences between early and late metastasis were seen for nuclear pleomorphism and to some extent for the mitotic score, but not for MAI. Interestingly, the type of tumour was also significantly different in this analysis, with the special types of tumour in the group of late distant metastasis. Other factors were not significantly different between the two groups.

\begin{tabular}{|c|c|c|}
\hline Patient selection & Controls (n) & Cases (n) \\
\hline $\begin{array}{l}\text { Tumour size } \geqslant 1 \mathrm{~cm} \text { and } B R \text { grade } 3 \text { or } \\
M A I \geqslant 10\end{array}$ & 13 & 20 \\
\hline Tumour size $\geqslant 1 \mathrm{~cm}$ and $B R$ grade 3 & 11 & 20 \\
\hline Tumour size $\geqslant 1 \mathrm{~cm}$ and $\mathrm{MAl} \geqslant 10$ & 11 & 14 \\
\hline
\end{tabular}


Table 5 Early versus late distant metastasis in cases, median 3.7 years

\begin{tabular}{|c|c|c|c|}
\hline Variable & Early & Late & p Value \\
\hline \multicolumn{4}{|l|}{ Tumour size } \\
\hline$\leqslant 1 \mathrm{~cm}$ & 2 & 5 & \\
\hline$>1$ and $\leqslant 1.5$ & 13 & 11 & \\
\hline$>1.5$ and $\leqslant 2$ & 10 & 9 & 0.547 \\
\hline \multicolumn{4}{|l|}{ Tumour size } \\
\hline$<1 \mathrm{~cm}$ & 0 & 3 & \\
\hline$\geqslant 1 \mathrm{~cm}$ & 25 & 22 & 0.235 \\
\hline \multicolumn{4}{|l|}{ BR grade } \\
\hline 1 & 2 & 9 & \\
\hline 2 & 8 & 11 & \\
\hline 3 & 15 & 5 & 0.008 \\
\hline \multicolumn{4}{|l|}{ BR grade } \\
\hline $1 / 2$ & 10 & 20 & \\
\hline 3 & 15 & 5 & 0.009 \\
\hline \multicolumn{4}{|l|}{ Mitotic score (BR) } \\
\hline 1 & 8 & 18 & \\
\hline 2 & 7 & 3 & \\
\hline 3 & 10 & 4 & 0.025 \\
\hline \multicolumn{4}{|l|}{ MAI } \\
\hline$<10$ & 15 & 21 & \\
\hline$\geqslant 10$ & 10 & 4 & 0.115 \\
\hline \multicolumn{4}{|c|}{ Pleomorphism score (BR) } \\
\hline 1 & 0 & 5 & \\
\hline 2 & 6 & 11 & \\
\hline & 19 & 9 & 0.006 \\
\hline \multicolumn{4}{|c|}{ Tubule formation score (BR) } \\
\hline 1 & 2 & 1 & \\
\hline 2 & 3 & 6 & \\
\hline 3 & 20 & 18 & 0.588 \\
\hline \multicolumn{4}{|l|}{ Tumour type } \\
\hline IDC & 25 & 18 & \\
\hline ILC & 0 & 5 & \\
\hline Other & 0 & 2 & 0.009 \\
\hline \multicolumn{4}{|l|}{ Multifocal } \\
\hline No & 23 & 22 & \\
\hline Yes & 2 & 3 & 1.000 \\
\hline \multicolumn{4}{|l|}{ Vessel invasion } \\
\hline No & 19 & 21 & \\
\hline Yes & 6 & 4 & 0.725 \\
\hline \multicolumn{4}{|l|}{ DCIS extensive } \\
\hline No & 17 & 19 & \\
\hline Yes & 8 & 6 & 0.753 \\
\hline \multicolumn{4}{|l|}{$\begin{array}{l}\text { res } \\
\text { DCIS grade }\end{array}$} \\
\hline 0 & 17 & 19 & \\
\hline 1 of 2 & 2 & 3 & \\
\hline 3 & 6 & 3 & 0.648 \\
\hline \multicolumn{4}{|l|}{ Screen detected } \\
\hline No & 6 & 5 & \\
\hline Yes & 19 & 20 & 1.000 \\
\hline Type of surgery & & & \\
\hline Amputation & 11 & 14 & \\
\hline Lumpectomy & 14 & 11 & 0.572 \\
\hline Radiotherapy & & & \\
\hline Yes & 14 & 12 & \\
\hline No & 11 & 13 & 0.777 \\
\hline Side & & & \\
\hline Left & 14 & 9 & \\
\hline Right & 11 & 16 & 0.256 \\
\hline Age & & & \\
\hline$<50$ & 10 & 6 & \\
\hline $50-69$ & 13 & 11 & \\
\hline $70+$ & 2 & 8 & 0.109 \\
\hline Incidence period & & & \\
\hline $1988-91$ & 4 & 8 & \\
\hline $1992-7$ & 21 & 17 & 0.321 \\
\hline
\end{tabular}

BR, Bloom and Richardson; DCIS, ductal carcinoma in situ; IDC, invasive ductal carcinoma; ILC, invasive lobular carcinoma; MAl, mitotic activity index.

\section{DISCUSSION}

Nowadays, patients with stage I breast cancer constitute a large group of patients with good prognosis. Nevertheless, adjuvant treatment is often considered in these patients, and several prognostic factors are used to select those who might benefit from this treatment. Our present study confirms the importance of several prognostic factors that can all be derived from a simple haematoxylin and eosin stained slide. In univariate analysis, we found significant differences for tumour size, Bloom and Richardson grade, nuclear pleomorphism, the number of mitotic figures, and vessel invasion, as has also been found by several other authors (recently reviewed by Mirza and colleagues ${ }^{5}$ ). In our present study, differences in disease free survival (DFS) cannot be explained by under staging because the number of lymph nodes examined was the same for both groups. Like others, ${ }^{14}$ we could not confirm a disadvantage for a high number of negative lymph nodes, as found by Camp et al. ${ }^{15}$

Tumour size is a well established prognostic factor, and here we confirm a difference with respect to DFS between small and large Tl tumours, even using multivariate analysis. Others have made similar observations in $\mathrm{Tl}$ tumours with respect to DFS, ${ }^{16-20}$ and also with respect to overall survival. ${ }^{16} 1721$

The importance of tumour grade is more heavily debated. ${ }^{22}{ }^{23}$ Grade, using different criteria, as in our present study, has been reported as a prognostic factor in stage I carcinoma. ${ }^{16}{ }^{24}$ Grading has been made more reproducible and consistent by the Nottingham modification of the Bloom and Richardson grading system. ${ }^{12}$ The reproducibility of this grading system has been tested and is acceptable,,$^{25-27}$ and seems to have a prognostic value with respect to DFS and death in small node negative cancers. ${ }^{1}{ }^{19-22} 2728$ However, some studies do not report a prognostic effect of grade in node negative tumours. ${ }^{29}$ In univariate analysis of pathological prognostic factors we also found a significant difference for tumour grade, but this was lost in multivariate analysis, as was the case in other studies..$^{21} 27$ Studies that did retain grade after multivariate analysis differ from our study by including a smaller number of prognostic factors, ${ }^{1}$ or by including only early relapses and no late relapses. ${ }^{28}$

\section{"Selection on the basis of size and tumour grade is superior to selection on the basis of size and mitotic activity index, which is thought to be equivalent"}

In our study, significance on univariate analysis of the number of mitotic figures is dependent on how the data are represented, which may explain some of the apparently conflicting results in the literature: it is significant when analysed as a continuous variable, whereas it is not significant when analysed as a discrete variable, whether it is $\mathrm{MAI} \geqslant 10$ versus $<10$ or whether there are three mitotic count score groups. These findings are in accordance with other reports, 2728 although yet other studies have found significant prognostic value in the analysis of non-continuous data. ${ }^{21}{ }^{30-33}$ These differences can be partly explained by the use of different thresholds for the number of mitotic figures, which were reported as between 0.2 and 30/10 high power fields, defining two and sometimes three groups of patients. ${ }^{21} 303234$ Another problem was the unbalanced distribution of cases according to the mitotic score, which adds to the difficulty of establishing a threshold. ${ }^{32}$ This illustrates that counting mitotic figures is not as simple as it seems. ${ }^{9}$ Nevertheless, a threshold value is needed if the mitotic activity is used in making therapeutic decisions.

Nuclear grade and tubule formation have been reported in the past as prognostic factors in stage I carcinoma. ${ }^{35}$ In our present study, we confirmed the prognostic value of nuclear grade, but not of tubule formation. However, nuclear grade was lost as a prognostic factor in multivariate analysis, as has been found by others. ${ }^{21}$ Genestie et al were also unable to confirm the prognostic value of these factors. ${ }^{32}$ The methods of scoring both nuclear grade and tubule formation have been criticised as poorly reproducible. ${ }^{36} 37$ 
The Nottingham modification of the Bloom and Richardson grading system is used for usual ductal carcinoma and also for special types of breast cancer, such as invasive lobular carcinoma, tubular carcinoma, and colloid carcinoma. Nevertheless, some studies show a better prognosis for some of these special types. ${ }^{16}{ }^{38}$ We were unable to confirm these findings, probably because of the low number of special tumour types included in our study. Tumour type did not make a difference for early or late distant metastases.

The presence of DCIS is mostly studied as a prognostic factor for local recurrence. Some authors suggest that high grade DCIS with casting-type calcifications is also a prognostic factor for distant recurrence. ${ }^{39}{ }^{40}$ Tabar et al made this suggestion based on the presence of casting-type calcifications on mammography, without correlating these findings with the pathological slides. ${ }^{39}$ The study of Zunzubegui et al included only 15 patients with high grade DCIS, precluding further analysis of their findings ${ }^{40}$ We were unable to confirm the prognostic value of high grade DCIS for DFS, as were Quiet et al. ${ }^{4}$

In our present study, vessel invasion is an important prognostic factor for DFS and it was still significant in multivariate analysis. Similar observations have been made by others in node negative breast cancer with respect to DFS, ${ }^{4} 161720284142$ and also for overall survival. ${ }^{17}{ }^{21}{ }^{41-43}$ In the study of Rosen et al, the prognosis of patients with TINO disease and lymph vessel invasion was worse than that of patients with TlNl disease, and they suggested that these patients should receive AST. ${ }^{17}$ Lauria et al also found the relative risk of death for lymph vessel invasion in node negative patients sufficiently high to suggest that these patients should receive adjuvant treatment. ${ }^{43}$ Vessel invasion is not always retained on multivariate analysis, ${ }^{28}$ and in some studies is not a prognostic factor. ${ }^{3}$

Prognostic factors are used in the selection of patients, including patients with stage I disease, for AST and/or hormonal treatment. We applied the selection criteria put forward in recent Dutch guidelines for AST to our study to see which patients would have been selected. ${ }^{6}$ Our results show that selection on the basis of size and tumour grade is superior to selection on the basis of size and MAI, which is thought to be equivalent. However, it can also be seen that the selection is not perfect because 30 of the 50 patients with distant recurrence would not have been selected for adjuvant treatment. In addition, 11 of the 50 control patients without distant recurrence would have been selected for AST. Offering adjuvant treatment to patients with a tumour size $\geqslant 1 \mathrm{~cm}$, as has been suggested, ${ }^{11}$ would select 47 of the 50 patients with distant metastases, but also 40 of the 50 patients without distant metastasis (table 2). It has to be remembered that we performed a case-control study, and that in the original population only 66 of the 561 patients with stage I disease had a distant recurrence, whereas 495 patients did not have a distant recurrence. This shows that the selection criteria for AST are still imperfect. A change in the threshold of the grade at which adjuvant treatment is offered was suggested as a solution to this problem. ${ }^{26}$ However, in our study the overlap in grading values between patients with a recurrence and those without is considerable, which suggests that this is not an attractive solution. It has been suggested in the past that patients with node negative breast cancer $1.1-2.0 \mathrm{~cm}$ in size with lymphatic tumour emboli should receive AST. ${ }^{16}{ }^{43}$ This prognostic factor has been included in the Canadian guidelines for adjuvant treatment in node negative cancer. ${ }^{10}$ Our data on vessel invasion support this strategy.

In a separate analysis of patients with distant metastases we used the median time of 3.7 years to distant metastasis to divide this group into cases with early and late metastasis.
Take home messages

- Tumour size and vessel invasion are the best prognostic factors for disease free survival in patients with stage I breast cancer

- The Dutch selection criteria for adjuvant systemic treatment for these patients need to be improved

- Some prognostic factors are time dependent, making their use as selection criteria for adjuvant systemic treatment more complicated

Comparison of these groups for Bloom and Richardson grade, mitotic index, and nuclear grade showed a highly significant difference, with grade 3, mitotic score 3, and nuclear grade 3 being associated with early distant metastasis. This suggests that these factors have a prognostic value depending on the duration of disease follow up. A similar observation was made by Page et al for tumour grade and mitotic index. ${ }^{27}$ Interestingly, the risk of recurrence of breast cancer is also time dependent, with two peaks - an early peak at about 18 months after surgery and a second peak at about 60 months. ${ }^{44}$ It has also been suggested that AST is effective in preventing some early recurrences, but is not effective in preventing late recurrences. ${ }^{45}$

In conclusion, our present study shows that tumour size and vessel invasion are the best prognostic factors for DFS in patients with stage I breast cancer. It also demonstrates that the selection criteria for AST for these patients need to be improved. In addition, we show that some prognostic factors are time-dependent, which makes the use of these factors as selection criteria for AST more complicated.

\section{Authors' affiliations}

P J Westenend, Pathologisch Laboratorium voor Dordrecht eo, Laan van Londen 1800, 3315 HG Dordrecht, The Netherlands

C J C Meurs, R A M Damhuis, Rotterdam Cancer Registry, PO Box 289, 3000 AG Rotterdam, The Netherlands

\section{REFERENCES}

1 Joensuu H, Pylkkanen L, Toikkanen S. Late mortality from pTINOMO breast carcinoma. Cancer 1999:85:2183-9.

2 Moon TE, Jones SE, Bonadonna G, et al. Development and use of a natural history data base of breast cancer studies. Am J Clin Oncol 1987; 10:396-403.

3 Neville AM, Bettelheim R, Gelber RD, et al. Factors predicting treatment responsiveness and prognosis in node-negative breast cancer. The international (Ludwig) breast cancer study group. J Clin Oncol 1992; 10:696-705.

4 Quiet CA, Ferguson DJ, Weichselbaum RR, et al. Natural history of nodenegative breast cancer: a study of 826 patients with long-term follow-up. J Clin Oncol 1995; 13:1144-51

5 Mirza AN, Mirza NQ, Vlastos G, et al. Prognostic factors in node-negative breast cancer: a review of studies with sample size more than 200 and followup more than 5 years. Ann Surg 2002;235:10-26.

6 Bontenbal M, Nortier JW, Beex LV, et al. [Adjuvant systemic therapy for patients with resectable breast cancer: guideline from the Dutch National Breast Cancer Platform and the Dutch Society for Medical Oncology]. Ned Tijdschr Geneeskd 2000;144:984-9.

7 Elston CW, Ellis IO. Assessment of histological grade. In: Elston CW, Ellis IO, eds. The breast. Edinburgh: Churchill Livingstone, 1998:365-84.

8 Van Diest PJ, Baak JP, Matze-Cok P, et al. Reproducibility of mitosis counting in 2,469 breast cancer specimens: results from the multicenter morphometric mammary carcinoma project. Hum Pathol 1992;23:603-7.

9 Thunnissen FB, Ambergen AW, Koss M, et al. Mitotic counting in surgical pathology: sampling bias, heterogeneity and statistical uncertainty. Histopathology $2001 ; 39: 1-8$

10 Adjuvant systemic therapy for women with node-negative breast cancer. The steering committee on clinical practice guidelines for the care and treatment of breast cancer. Can Med Assoc J 1998;158(suppl 3):S43-51.

11 Aapro MS. Adjuvant therapy of primary breast cancer: a review of key findings from the 7th international conference, St Gallen, February 2001 Oncologist 2001 ;6:376-85. 
12 Elston CW, Ellis IO. Pathological prognostic factors in breast cancer. I. The value of histological grade in breast cancer: experience from a large study with long-term follow-up, Histopathology 1991;19:403-10.

13 Holland R, Peterse JL, Millis RR, et al. Ductal carcinoma in situ: a proposal for a new classification. Semin Diagn Pathol 1994;1 1:167-80.

14 Moorman PG, Hamza A, Marks JR, et al. Prognostic significance of the number of lymph nodes examined in patients with lymph node-negative breast carcinoma. Cancer 2001;91:2258-62.

15 Camp RL, Rimm EB, Rimm DL. A high number of tumor free axillary lymph nodes from patients with lymph node negative breast carcinoma is associated with poor outcome. Cancer 2000;88:108-13.

16 Rosen PP, Saigo PE, Braun DW Jr, et al. Predictors of recurrence in stage I (TINOMO) breast carcinoma. Ann Surg 1981;193:15-25.

17 Rosen PP, Groshen S, Saigo PE, et al. Pathological prognostic factors in stage I (TINOMO) and stage II (TINIMO) breast carcinoma: a study of 644 patients with median follow-up of 18 years. J Clin Oncol 1989:7:1239-51.

18 Carter CL, Allen C, Henson DE. Relation of tumor size, lymph node status, and survival in 24,740 breast cancer cases. Cancer 1989;63:181-7.

19 Rosner D, Lane WW. Predicting recurrence in axillary-node negative breast cancer patients. Breast Cancer Res Treat 1993;25:127-39.

20 Lee AK, Loda M, Mackarem G, et al. Lymph node negative invasive breast carcinoma 1 centimeter or less in size (Tla,bNOMO): clinicopathologic features and outcome. Cancer 1997;79:761-71.

21 Clayton F. Pathologic correlates of survival in 378 lymph node-negative infiltrating ductal breast carcinomas. Mitotic count is the best single predictor. Cancer 1991;68:1309-17.

22 Roberti NE. The role of histologic grading in the prognosis of patients with carcinoma of the breast: is this a neglected opportunity? Cancer 1997;80:1708-16.

23 Burke HB, Henson DE. Histologic grade as a prognostic factor in breast carcinoma. Cancer 1997;80:1703-5.

24 Henson DE, Ries L, Freedman LS, et al. Relationship among outcome, stage of disease, and histologic grade for 22,616 cases of breast cancer. The basis for a prognostic index. Cancer 1991;68:2142-9.

25 Dalton LW, Page DL, Dupont WD. Histologic grading of breast carcinoma. A reproducibility study. Cancer 1994;73:2765-70.

26 Dalton LW, Pinder SE, Elston CE, et al. Histologic grading of breast cancer: linkage of patient outcome with level of pathologist agreement. Mod Pathol 2000; 13:730-5.

27 Page DL, Gray R, Allred DC, et al. Prediction of node-negative breast cancer outcome by histologic grading and S-phase analysis by flow cytometry: an eastern cooperative oncology group study (2192). Am J Clin Oncol $2001 ; 24: 10-18$.

28 Colpaert C, Vermeulen P, Jeuris W, et al. Early distant relapse in "nodenegative" breast cancer patients is not predicted by occult axillary lymph node metastases, but by the features of the primary tumour. J Pathol 2001;193:442-9.

29 Pinder SE, Murray S, Ellis IO, et al. The importance of the histologic grade of invasive breast carcinoma and response to chemotherapy. Cancer 1998;83:1529-39.
30 Biesterfeld S, Noll I, Noll E, et al. Mitotic frequency as a prognostic factor in breast cancer. Hum Pathol 1995;26:47-52.

31 Van Diest PJ, Baak JP. The morphometric prognostic index is the strongest prognosticator in premenopausal lymph node-negative and lymph nodepositive breast cancer patients. Hum Pathol 1991;22:326-30.

32 Genestie C, Zafrani B, Asselain B, et al. Comparison of the prognostic value of Scarff-Bloom-Richardson and Nottingham histological grades in a series of 825 cases of breast cancer: major importance of the mitotic count as a component of both grading systems. Anticancer Res 1998;18:571-6.

33 Clahsen PC, van de Velde CJ, Duval C, et al. The utility of mitotic index, oestrogen receptor and $\mathrm{Ki}-67$ measurements in the creation of novel prognostic indices for node-negative breast cancer. Eur J Surg Oncol 1999;25:356-63.

34 Thor AD, Liu S, Moore DH, et al. Comparison of mitotic index, in vitro bromodeoxyuridine labeling, and MIB-1 assays to quantitate proliferation in breast cancer. J Clin Oncol 1999;17:470-7.

35 Fisher B, Redmond C, Fisher ER, et al. Relative worth of estrogen or progesterone receptor and pathologic characteristics of differentiation as indicators of prognosis in node negative breast cancer patients: findings from national surgical adjuvant breast and bowel project protocol B-06. J Clin Oncol 1988;6:1076-87.

36 Kronqvist $P$, Kuopio T, Pirvu $C$, et al. The fraction of fields showing neoplastic tubules: a practical estimate of tubular differentiation in breast cancer. Histopathology 1999;35:401-10.

37 Dunne B, Going JJ. Scoring nuclear pleomorphism in breast cancer. Histopathology 2001;39:259-65

38 Ellis IO, Galea M, Broughton N, et al. Pathological prognostic factors in breast cancer. II. Histological type. Relationship with survival in a large study with long-term follow-up. Histopathology 1992;20:479-89.

39 Tabar L, Chen HH, Duffy SW, et al. A novel method for prediction of long-term outcome of women with $\mathrm{Tla}, \mathrm{Tl}$, and 10-14 mm invasive breast cancers: a prospective study. Lancet 2000;355:429-33.

40 Zunzunegui RG, Chung MA, Oruwari J, et al. Casting-type calcifications with invasion and high-grade ductal carcinoma in situ: a more aggressive disease? Arch Surg 2003;138:537-40.

41 Lee AK, DeLellis RA, Silverman ML, et al. Prognostic significance of peritumoral lymphatic and blood vessel invasion in node-negative carcinoma of the breast. J Clin Oncol 1990:8:1457-65.

42 de Mascarel I, Bonichon F, Durand M, et al. Obvious peritumoral emboli: an elusive prognostic factor reappraised. Multivariate analysis of 1320 nodenegative breast cancers. Eur J Cancer 1998;34:58-65

43 Lauria $\mathbf{R}$, Perrone $F$, Carlomagno $C$, et al. The prognostic value of lymphatic and blood vessel invasion in operable breast cancer. Cancer 1995;76:1772-8

44 Demicheli R, Abbattista A, Miceli R, et al. Time distribution of the recurrence risk for breast cancer patients undergoing mastectomy: further support about the concept of tumor dormancy. Breast Cancer Res Treat 1996:41:177-85.

45 Demicheli R, Miceli R, Brambilla C, et al. Comparative analysis of breast cancer recurrence risk for patients receiving or not receiving adjuvant cyclophosphamide, methotrexate, fluorouracil (CMF). Data supporting the occurrence of "cures". Breast Cancer Res Treat 1999;53:209-15. 